\title{
ADOPTION COMPLEXITY AND ECONOMIES OF SCOPE FOR NEW PROCESS TECHNOLOGY IN MANUFACTURING
}

\author{
JOHN E. ETTLIE \\ The University of Michigan \\ JOAN D. PENNER-HAHN \\ The University of Michigan
}

\begin{abstract}
In a study of 39 domestic, durable goods plants, justifications for purchase of new process technology varied from the simple, single-goal approach to the complex, multiple-objective strategy. This variety contributes to a larger construct of adoption complexity, which was found to be a function of flexible manufacturing systems (FMS) (vs. cellular) purchase choice and plant size in a significant path model. Adoption complexity, in turn, significantly influences intrafirm personnel flows for implementation (e.g., mobility and job rotation). Flexible outcomes are not automatic with FMS purchase, however. Part family variety was significantly higher in larger plants and part variety was significantly promoted by personnel flows. Suggestions for further research and policy implications are discussed.
\end{abstract}

Individuals routinely confront ill-structured, complex problems that challenge their cognitive capacities. Previous research has suggested that individuals simplify their situations considerably and grasp them with limited success due to bounded rationality and limited information (March \& Simon, 1958; O'Reilly, 1983; Simon, 1957). This process of simplification has been connected with a number of managerial failures including the saturation bombing of Europe in World War II (Wilensky, 1967) and the Bay of Pigs invasion (Wyden, 1979). Further, Walsh (1988) has compiled a list of suboptimal information processing strategies which have appeared in the literature over the last thirty years. These include such problems as selective perception (Dearborn

Direct all correspondence to: John E. Ettlie and Joan D. Penner-Hahn, School of Business Administration, The University of Michigan, Ann Arbor, MI 48109-1234.

The Journal of High Technology Management Research, Volume 5, Number 1, pages 19-38.

Copyright $\odot 1994$ by JAI Press, Inc.

All rights of reproduction in any form reserved.

ISSN: $1047-8310$. 
\& Simon, 1958), perceptual screens (Cyert \& March, 1963), personal bias (Stagner, 1969), collective blindness (Turner, 1976), and tunnel vision (Mason \& Mitroff, 1981). Roskin and Margerison (1984) found that higher achieving managers had more complex models of the technical side of job demands than did lower achieving managers.

Organizations, too, face ill-structured, complex problems that challenge their capabilities. One pervasive example of complex decision-making is that of the adoption of innovative processing technologies. Grinyer and Norburn (1975) found that more profitable firms use more diverse information to evaluate their performance outcomes than do less profitable firms. A comparable process likely takes place when decision makers are confronted with the prospect of understanding new processing technologies. What is more, people learn as they implement these technologies and this is reflected in their evolving view of the purchase decision. For example, Adler and Clark (1991) found that training and engineering design changes after new electronics system implementation can have an important impact on the learning curve-often negative, if temporary. This process is especially lively for manufacturing systems that incorporate radically new technology (Dewar \& Dutton, 1986).

\section{The Adoption Decision}

The recent literature on adoption of innovations gives some insight into the nature of the decision-making process in this type of setting. For example, Farley, Kahn, Lehmann, and Moore (1987) sampled 29 senior manufacturing managers in the U.S. and asked questions about the decision to automate. Cost reduction was considered the most important reason for automation. The decision to automate (converting attitudes into intentions and then into actions) was very much influenced by past experience with automation. Further, management typically was future oriented when they adopt new processing technology, but problems of making new processes work are not well understood when these decisions are made.

Another recent empirical study on change in process technology, or as the authors call it, "change in automaticity of production technologies," is presented by Collins, Hage, and Hull (1988). Automaticity is defined and measured as the proportion of automated machinery actually implemented in a plant. Again, history of adoption of technology proved to be a factor in implementation of change over time. But the impact of the history of tcchnology adoption, or lack thereof, was not what one might think. Those with lcss technology in 1973 had the greatest change in technology over the study period, as if they had to catch up to the rest of their industry. There were also results in the Collins et al. study to suggest that plants are beginning to innovate simultaneously in product and process. This suggests that one might necessitate the other. For example, a change in product might cause new production equipment to be purchased, or vice-versa.

\section{ADOPTION COMPLEXITY}

Members of a decision-making team in a typical manufacturing firm make certain assumptions about the relationship between customers' actions, competitor behavior, technology trends, government regulation, and the like. These assumptions are likely to be affected by internal capabilities like labor, proprietary technology, production 
capacity, etc. A special case of the application of these assumptions and perceptions occurs when a business unit embarks upon significant process modernization. The aggregate of these assumptions and perceptions influences the complexity of the justification process for technology choice (not supplier selection, per se). Based on the work of Fredrickson and Iaquinto (1989), it is likely that there is going to be great variance in approaches to justification. Here it is the multidimensionality of justification and sources of information for a significant course of action that is of great interest. For this initial treatment of the concept, the details of the choice are not part of the rationale. Rather, it is the complexity (goals and information) of the rationale that matters.

In conceptualizing adoption complexity, many authors have made relevant contributions. For example, Weick (1979) has argued, convincingly, that the adaptiveness of groups was very strongly influenced by their tolerance for deviant and divergent opinion. That is, environmental challenges require behaviors which are new and innovative. If groups (or organizations) have not tolerated the deviant voice or contrary opinion, they will not have this "variance" to call on when innovation is required by the situation. It follows that complexity of adoption decisions would be less under these lower variance situations. Others (e.g., Burstein \& Graham, 1989) have concentrated on formalization of the justification process with cmphasis on the incorporation of market concerns. It could be argued that going beyond traditional payback models that use direct labor savings alone in justification, adds to the complexity of the adoption process.

Therefore, one interpretation of the application of comprehensiveness to purchase rationale complexity reflects the divergence of opinion tolerated-many voices truly incorporated into a decision-and a strategic choice selected that represents a healthy tension between "agreement" and "disagreement" on a calculated risk path for the organization. This tension may not actually specify the action required, only the riskiness of course of action. Just as individuals vary in their tolerance for ambiguity and risk, and in their cognitive complexity, so do groups and organizations. This will be reflected in, and manifested by, the breadth of influences on a major purchase decision. One impact of this breadth is the resulting comprehensiveness of the approach. A review of the measures used in previous research on this construct is presented in Table 2 later. This includes work on planning (Wood \& I aforge, 1981), and international differences in the outcomes of the planning process (Hagarty \& Hoffman, 1990).

Assuming previous research is a reasonable guide, the rationales for major decisions like investment in new product-process technology provide one view or window on organizational decision making. The causes and effects of adoption complexity can then be used to understand not only the decision-making process in an organization, but also one aspect of the nature of the learning process during significant change.

\section{PROPOSITIONS}

Organizations need motivation and opportunity to inculcate more complex and comprehensive models of the decision-making process. For example, in the case of major process changes in manufacturing, firms would need a motivation to turn away from the traditional economic justification mechanism which usually requires that new equipment replace direct labor costs. It is assumed that adopting units vary in the degree of complexity and rigor they gradually assign to the purchase decision, including the 
period after the choice has been made. The focus here is on conceptualizing and measuring this adoption rationale complexity, as well as the causes and consequences of this approach in the purchase decision for modernization.

In the quest to model process innovation decision-making complexity it assumed that the more clearly delineated reasons - potentially independent - that are actually aired during the adoption process, the more complex the rationale (Kaplan \& Atkinson, 1989). What is more, we assume that organizations actually learn during the change process because functional or discipline representatives often share views and the residue of this learning is reflected in part in the complexity of the rationale (Hage, 1980). Marketing both agrees and disagrees with engineering, for example.

We focus on two primary predictors here: technology choice and structural complexity - as reflected by size. Fredrickson and Iaquinto (1989) found that changes (increases) in organization size were significantly correlated with increases in strategic decision-making comprehensiveness (see Table 2). In stable environments, comprehensiveness and organizational performance were positively related. A plausible rival hypothesis is that environmental complexity (vs. dynamism) increases the need for comprehensiveness and the need for innovativeness (Freeman, 1982). It could be argued that choice of technology is influenced by environmental uncertainty, which is manifest in new technology incorporated (e.g., radical) as well as the more fundamental strategy for change. In particular, whether or not a more flexible technology is chosen will determine the scope (and scale) of new operations.

This by no means exhausts all causes of decision rationale complexity and this study should be considered exploratory. Many authors define business environment as the degree to which growth via innovative new products is exhibited by competitors (Hambrick, 1983). This type of competition causes the introduction of new products which, in turn, causes production processes to change (Ettlie, Bridges, \& Okeefe, 1984). As product-process systems change more rapidly, purchase rationales became more complex. It is this process system change that is the focus of this study.

The second predictor included here is organizational structural complexity as reflected by the size of the adopting unit. Larger units are almost always more complex in their structures, especially when innovation is the preoccupation (Ettlie et al., 1984). The more complex the decision unit, the more difficult to manage. This leads to more complex rationales for modernization which usually require at least minor changes in structurc (Kolodny \& Stjernberg, 1986).

The consequences of adoption complexity may actually be more difficult to predict than Fredrickson and Iaquinto (1989) suspected in their more general approach to strategy. Skinner (1986) contends that the "productivity paradox" in manufacturing exists because facilities are not focused on customers. Only when customers and markets are directly satisfied, regardless of levels of performance on traditional measures (productivity), is a manufacturing organization successful. Therefore, it is predicted that if a manufacturing firm uses a complex adoption rationale for modernization, it would better understand this causal connection to effectiveness. That is, a complex adoption rationale would impact market and customer oriented outcomes and not necessarily relative success on productivity measures of new system performance. Jaikumar (1986) found that U.S. firms rarely take advantage of flexible manufacturing systems vis-à-vis the Japanese.

Hagarty and Hoffman (1990) have found that comprehensive planners perform better, regardless of culture (Anglo versus Germanic versus Nordic). But some cultures 
emphasize return on sales (Anglo), others, return on assets (Germanic), still others, sales growth (Nordic).

The literature on economies of scope (vs. scale) is quite clear about the role of flexibility in satisfaction of customer needs (e.g., Goldhar \& Jelinek, 1983, 1990). The most recent delineation of this concept and connection is summarized in Milgrom and Roberts (1990). An essential feature of the theory of scope is that there be ease of movement from one product group to another rather than long runs of large batches. Flexibility is a profound feature in making economies of scope work in manufacturing (Lim, 1987; Gerwin \& Tarondeau, 1988). Part variety, per se, is not a sufficient indicator of scope (Ettlie, 1988). Further, recall that Adler and Clark (1991) found that training and design changes-with the intention of enhancing learning-actually reduced productivity gains temporarily after new system introduction.

What remains to be specified in this model of causes and consequences of adoption complexity is the intervening mechanism by which strategy (complex rationale) is implemented to cause outcomes (greater scope through flexibility). In this study the general mechanism that is proposed, given that structural complexity is approximated by plant size, is personnel flow. In particular, intrafirm flow of people during implementation of the decision is predicted to be the intervening mechanism by which complex strategies for adoption are carried out. The intraorganizational mobility of key personnel (manufacturing engineers) following adoption (Ettlie, 1985, 1990) has already been shown to be important for other modernization outcomes. Here it is suggested that it is one important intervening mechanism to realize a complex justification strategy.

The four propositions which summarize this model are presented next.

P1: The adoption complexity of the purchase rationale for new processing systems in manufacturing is likely to be a function of both the type of system chosen (FMS vs. cells and radical vs. incremental technology) as well as the structural complexity of the adopting unit. When FMS is chosen over new cells or other new processing technologies, and in larger plants, it is likely to result in a more complex adoption process.

P2: Personnel flows (mobility and rotation) are likely to be one of the primary intervening mechanisms by which a complex adoption decision is converted into flexible outcomes of production. People carry and have experiences reinforced when they are promoted.

P3: Technology choice (FMS vs. cells and radical vs. incremental technology) is unlikely to influence flexible outcomes directly. Rather, it is likely to function indirectly through adoption complexity and personnel flow to influence realized flexibility and economies of scope.

P4: Structural complexily (size is a proxy) and personnel flows are likely to influence part family variety (more difficult scope challenge) rather than part variety (less difficult scope challenge).

These four propositions are incorporated in the proposed causal model for testing and presented in Figure 1 below. 


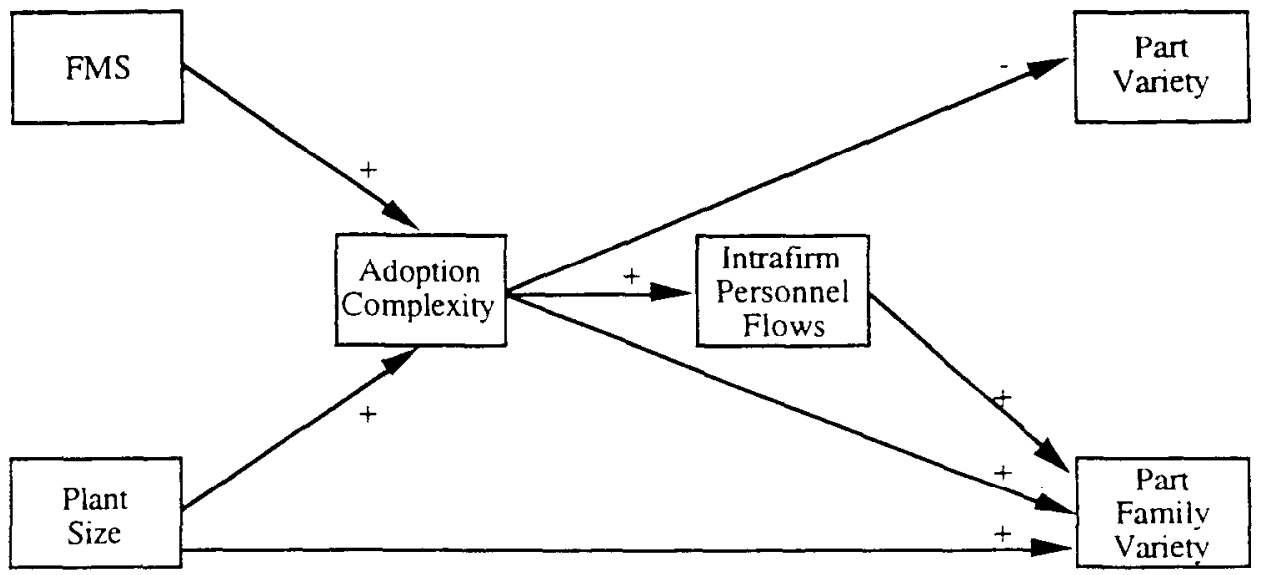

\section{FIGURE 1 \\ Proposed Causal Model and Propositions}

\section{METHODOLOGY}

We randomly sampled firms that announced major, new manufacturing system adoption and two-thirds agreed to participate. In all cases firms, plants and individuals were guaranteed anonymity and 39 plants agreed to interviews at the site of the modernization project. Respondents provided information in order that the nature of purchase rationale could be evaluated. The test of the causal model using this approach was considered an exploratory first step in the research process.

\section{Sample}

The original sample was compiled by merging lists of announcements of significant, multiple component, flexible manufacturing and assembly systems from several sources. Trade publications like Automation News, Metalworking News, all major robotics publications, and American Machinist were screened by independent researchers for announcements of system purchases. We confined ourselves just to the discrete product industries so the population eventually became bounded by SIC 34-37.

In order to be eligible for the study, a firm was required to have committed resources for the purchase of the system, although not necessarily to have installed the system as yet. A total of $39(66 \%)$ of the first 59 eligible plants we contacted by letter agreed to participate in the study. Cases were screened by phone first to find a person in charge. About half were flexible manufacturing systems (FMS) defined in very broad termsmultiple machine, materials handling intensive, and computer-integrated systems. The other half were flexible assembly systems. Although flexible assembly systems reduced labor costs more than FMS, there were no other significant differences between the plants that adopted these two types of technologies. Data used here were collected in 1987. All firms themselves had multiple plant operations, but one-way analysis of variance found same-firm participating plants to be independent. 
Industry comparisons were also done by major grouping (2-digit SIC), as well as size of firm and plant with no significant differences detected (one-way analysis of variance). The exception was the tendency for larger firms to be unionized. However, unionization was not correlated with any other factor. Median system cost was \$3-4 million. The minimum investment was $\$ 190,000$; maximum was $\$ 50$ million.

Participating plants were operated by primarily large firms, with the vast majority having more than 500 employees, and covering all the major discrete parts, batch and mass manufacturing categories of transportation equipment, fabricated metal products, and electrical or other equipment. Plants were also large, with about 60 percent having more than 500 employees. All regions of the country were well represented in the sample which included one Canadian plant. It is important to note that this sample does not represent all durable goods manufacturers, but rather a more select set of organizations already introducing advanced manufacturing processing change.

Perhaps the best way to put this sample into perspective is to review the findings of the U.S. Department of Commerce Bureau of Census survey completed in September 1988, titled “Manufacturing Technology 1988," which appeared in May of 1989. In other words, this DOC survey and our data were taken at approximately the same time. This report summarizes the most comprehensive survey of this type to datc. Of 39,556 establishments responding, 4,217 said they were using flexible manufacturing cells or systems $(10.7 \%)$. Another 1,683 said they planned to use FMS within two years. Another 2,861 said they planned to use FMS within the next five years. A total of $18,199(46 \%)$ of these responding units said FMS was not appropriate for their manufacturing operations. At the most then, our sample only represents about half the population of manufacturing in the U.S.

Over 100 personnel were interviewed at the plants where new systems were installed. Data collection started late in the fall of 1987 but was completed primarily in the spring of 1988. One of the authors did about half of all interviews. A second interviewer (not an author) did the rest. One primary respondent was identified in each case, although we usually interviewed two or three people at each plant to gather information from the "expert" on site. These primary respondents were most often general managers (20) with fewer middle managers (10), but combined they accounted for 76.9 percent of the primary information persons.

\section{Size}

Plant size (adopting unit) was measured by the number of full-time, year-round employees at that plant site. These data were obtained in interviews. It was taken as a proxy for structural complexity (e.g., Ettlie et al., 1984).

\section{Technology Choice}

Technology choice data resulted from documenting, at length, and in interviews, the system configuration and part flow. The systems were broadly categorized as FMS (flexible manufacturing systems) that had multiple, similar purpose types of equipment, like milling machines versus cells, that had nonredundant components, like a grinding station, a broach, etc. The contention here is that FMS is generally a more challenging system to adopt, holding radicalness of technology constant, which is discussed next. 
A total of $20(51 \%)$ of these plants adopted FMS systems and $19(49 \%)$ were cells or flexible assembly systems. All represented substantial, new production technologies to the plants involved in the study, but varied on type of technology incorporated. FMS was coded one for "yes" and zero for "no."

\section{Radicalness of Technology}

Radicalness of technology was included to evaluate the rival hypothesis that purchase rationale complexity reflects technology complexity, not organizational changes. This variable was measured in each system by a panel of six expert (process engineer) judges, selected at random from a local research institute. They used the following protocol:

1) radical technology is a rare event, e.g., typically only 10 percent of all new products introduced each year are new to the world (Booz, Allen, \& Hamilton, 1982);

2) radical technology incorporation involves new science that is a demonstrable departure from existing practice, e.g., cutting metal bars with lasers versus saws;

3) new technology that is radical is risky to adopt bccause of lack of precedent in use, and the outcomes in practice are uncertain (Hage, 1980); and

4) radical technology requires new skills and attitudes to deploy, and a learning curve effect is observed when it goes into use.

For the radical category alone there was a 77 percent agreement between one of the authors and the panel of six engineers on categorization of radical system cases.

In this coding exercise, the results of this case data were presented to these engineers, and this group of expcrts agreed on five additional criteria for the protocol specific to this arena of technology supply in manufacturing modernization:

1) level of integration of the system;

2) flexibility;

3) machine intelligence;

4) robustness-or degree of effective operation in a degraded performance mode; and

5) the number of new features incorporated into a system.

Five of the 39 cases were coded as radical technology systems after replacement for attrition. A more limited set of three of the same judges was used to check categorization of the replacement cases with continued high agreement on type of technology incorporated in the systems studied.

\section{Adoption Complexity}

A scale with six items was developed to measure adoption complexity. The focus of the first item is on purchase complexity. Respondents were asked: "Why was the system purchased"? with a prompt to interviewers noting that we were not interested in supplier choice here but why the firm decided to modernize. The frequency count of reasons appears in Table 1. Note that productivity, which includes cost reduction, 
TABLE 1

Why Do Firms Purchase New Manufacturing Technology?

\begin{tabular}{|c|c|c|c|}
\hline \multicolumn{2}{|r|}{ Reported Purchase Reason ${ }^{1}$ (Post-Adoption) } & \multicolumn{2}{|c|}{$f(\%)$} \\
\hline 1. & Productivity Enhancement $^{2}$ & 17 & $(44 \%)$ \\
\hline 2 . & Quality & 5 & $(13 \%)$ \\
\hline 3. & Learn About New Technoogy & 5 & $(13 \%)$ \\
\hline 4. & New Product & 4 & $(10 \%)$ \\
\hline \multirow[t]{3}{*}{5.} & Miscellaneous (e.g., Safety, Markting, Flexibility, Good Buy on & & \\
\hline & Equipment, Capacity, ROI, Machine Replacement) & 8 & $(20 \%)$ \\
\hline & & 39 & $(100 \%)$ \\
\hline
\end{tabular}

Notes: 1 The first, or most important reason or rationale. Only 10 of 39 plant case representatives gave single reasons; 15 cases gave two reasons for adoption; eight cases gave three reasons; four case gave four reasons; one case gave five reasons; and one case six reasons.

Includes cost reduction.

was mentioned most often, as in the Farley, et al. (1987) study. A total of 10 of the 39 cases gave single post-purchase reasons for adoption (Table 1). Data for purchase reason were coded in the following manner: each separate reason was noted (e.g., direct labor cost reduction, quality, competition, etc.); then, a sum or total count of individual reasons was made (after Ettlie \& Rosenthal, 1987). The total score constituted the purchase complexity item (mean $=2.3$ reasons, standard deviation $=1.1$ ). The greatest number of reasons given was six (one case), one case gave five reasons, four cases gave four reasons, eight cases gave three reasons each, 15 cases gave two reasons, and 10 cases gave one reason.

Coding of purchase complexity was grounded in interview experiences. In numerous cases, respondents gave elaborate "causal" models of the justification process. For example, as inventory declines or quality improves, costs come down, which allow funds to be allocated for software and attention to be refocused on maintenance. There were many scenarios like the Fredrickson and Iaquinto (1989) approach recounted. The Fredrickson approach actually uses a hypothetical firm confronted with the decision to build new, state-of-the-art production facilities, and codes the analysis of this decision situation. Here we study the actual decision to adopt new processing technology.

Further, it is believed that these findings replicate the Minnesota Innovation Research Program methodological result that there exist "phases" in the innovation process (Van de Ven \& Poole, 1990). They define a phase as "a period of unified and coherent activity that serves as some innovation function" (Van de Ven \& Poole, 1990, 329). Simultaneous activities are coded on constructs or "tracks of events." The rationale for major technology purchases represents a significant phase in the innovation process. Further, if these stages (pre- and post-adoption) overlap, it means that terms like "implementation" will begin to lose their meaning while terms like "institutionalization" (March \& Simon, 1958) take on ncw mcaning because stagcs overlap to form phases.

The remainder of scale items (five) were compiled using interview questions from sections of the interview guide on structural change, design and product development practices, and changes in relationships with suppliers and customers. The item analysis program used was SPSSx, and the validity of these items and scale characteristics of all six items is presented in Table 2 . We restricted respondents to behaviors and actions 


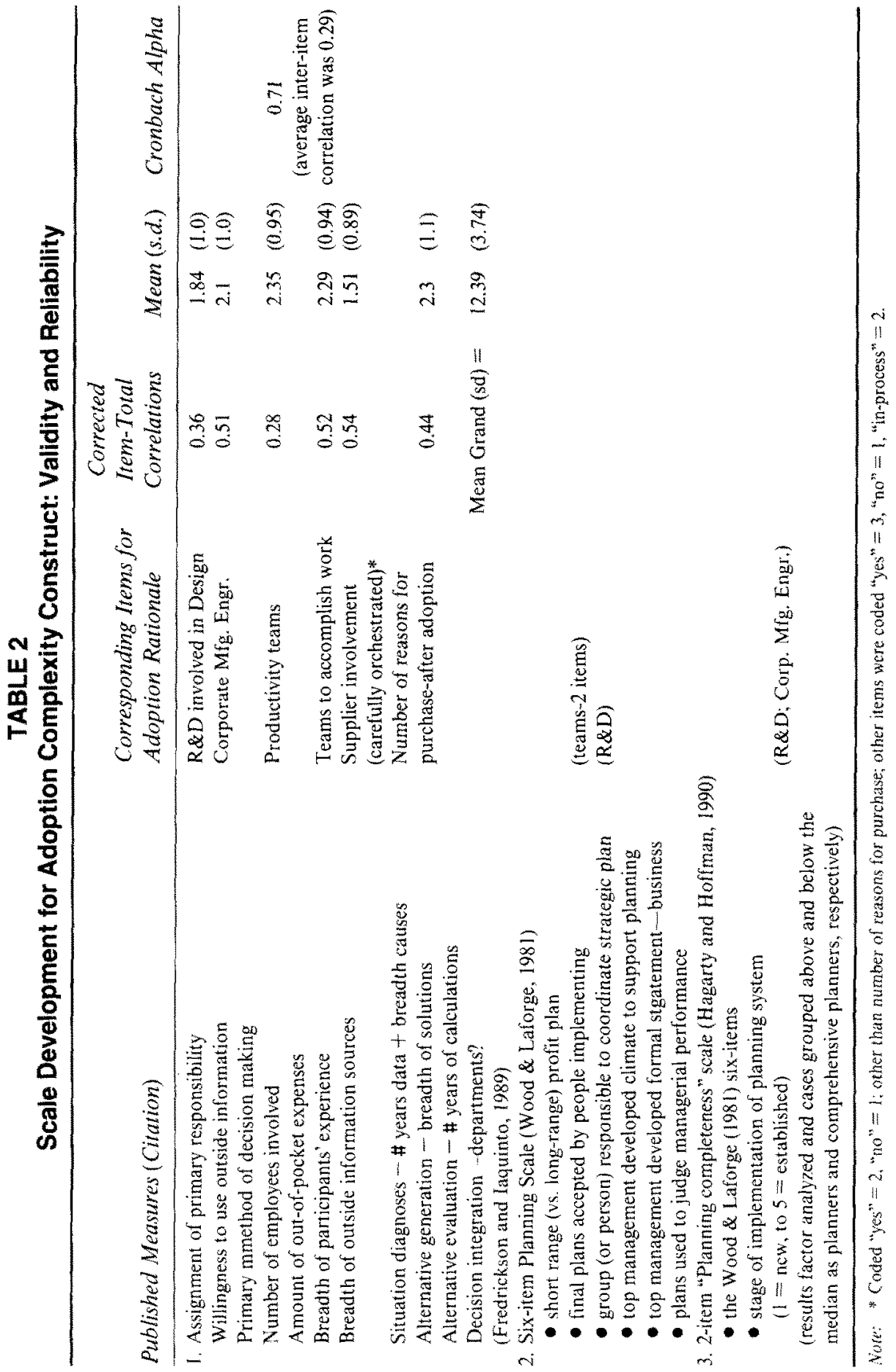


only-not attitudes or beliefs. Therefore, options for responding to a particular question were limitcd on most occasions to "yes," "no," or "in process." These responses werc ultimately coded 3,1 , and 2 , respectively, in order to avoid confusion with coding "0" as missing. For the purposes of scale development for dichotomous or limited category response formats, this procedure is justified (Kim \& Mueller, 1978, p. 75).

The actual items that were eventually included in the scale, in addition to the purchase rationale reason count, were as follows:

1) "We use teams in the system to accomplish work;"

2) "We have productivity teams;"

3) "Our R\&D unit was involved in the designing of this system;"

4) "We have a corporate manufacturing function;" and

5) "Is it ever to early to include suppliers in a program for modernization?" "Yes" coded 3, "No" coded 1).

This last item (actually item number six in the Appendix where the questions are reproduced), is quite interesting because it scores cases higher on comprehensiveness if they are slower to involve suppliers-that is, they get their strategy in place first, before suppliers are involved. This is a very subtle point and makes this scale harder to "fake." There is a tendency for respondents to say that it is never too early to involve suppliers. Complex planners disagree. It may be too early to involve them - it depends. This comes out in the "explanation" part of the question.

The corrected item-total correlation coefficients are reported in Table 2, along with the indicators from three previous studies on the comprehensiveness concept. Each item that made the scale has at least one precedent in a previous study. For example, purchase reason frequency count is similar to the situation analysis and alternative generation breadth indicators used by Fredickson and Iaquinto (1989). The R\&D involvement item and use of corporate manufacturing engineering for planning is consistent with the precedent of using assignment of primary responsibility, willingness to use outside information, and having top management committed to creating a climate for planning used in two previous studies (Table 2). The use of teams is consistent with the previous indicators of having groups responsible to coordinate plans, the number of employees, and the out-of-pocket expenses for planning. Stage of implementation of the planning effort, used before, applies across the board to the new scale but to $R \& D$ and corporate engineering items in particular. The face validity of this scale appears to be quite acceptable and with a Cronbach alpha of 0.71 (average interitem correlation $=0.29$ ), internal consistency is well above the minimum 0.50 and close to the more typical coefficient of 0.80 (Nunnally, 1978). Overall, summed (six-item) scale mean was 12.39 with a standard deviation of 3.74 for 31 complete data cases.

\section{Personnel Flows}

Each key interview respondent was asked the following question (Ettlie, 1990): "Has there been any significant movement of personnel associated with this project since it began? (Probe: turnover, promotion, vendor personnel changes, added new team members.)" The Yes answer was coded one, No answers were coded zero. 
When responses were coded, turnover was excluded and allocated to another question on personnel turnover. There were 36 valid answers, $22(56.4 \%)$ of the 39 cases were yes. The slim majority of the data related to movement of manufacturing engineers (Ettlie, 1990); only intrafirm movements were coded because interorganizational transfers were rarely reported.

\section{Outcome Variables}

Two dependent variables were included in this analysis and compiled from company records: the number of parts scheduled on the new system, called part variety; and the number of part families scheduled called part family variety.

\section{RESULTS}

Descriptive statistics and the matrix of Pearson $r$ correlation coefficients for all available data cases are presented in Table 3. Mean substitution (SPSSx) was used to estimate missing data and pair-wise deletion coefficients are presented in Table 3 . The path model is presented in Figure 2.

\section{TABLE 3}

Correlation Matrix and Descriptive Statistics ${ }^{1}$

\begin{tabular}{|c|c|c|c|c|c|c|}
\hline & 1 & 2 & 3 & 4 & 5 & 6 \\
\hline 1. Technology choice $(\mathrm{FMS}=)$ & () & & & & & \\
\hline 2. Plant Size (\# employees) & $\begin{array}{c}0.13 \\
(n=39 \\
p=0.22)\end{array}$ & ( ) & & & & \\
\hline 3. Adoption Complexity & $\begin{array}{c}0.39 * \\
(n=32 \\
p=0.007)\end{array}$ & $\begin{array}{c}0.38^{*} \\
(n=31 \\
p=0.008)\end{array}$ & $(0.71)$ & & & \\
\hline 4. Intrafirm Personnel Flow & $\begin{array}{c}0.11 \\
(n=36 \\
p=0.25)\end{array}$ & $\begin{array}{c}0.19 \\
(n=36 \\
p=0.13)\end{array}$ & $\begin{array}{c}0.42^{*} \\
(n=28 \\
p=0.004)\end{array}$ & $($ ) & & \\
\hline 5. Part Variety & $\begin{array}{c}-0.15 \\
(n=24 \\
p=0.18)\end{array}$ & $\begin{array}{c}-0.03 \\
(n=24 \\
p=0.42)\end{array}$ & $\begin{array}{c}-0.27 * * \\
(n=23 \\
p=0.046)\end{array}$ & $\begin{array}{c}0.18 \\
(n=23 \\
p=0.14)\end{array}$ & $($ ) & \\
\hline 6. Part Family Variety & $\begin{array}{c}0.17 \\
(n=20 \\
p=0.15)\end{array}$ & $\begin{array}{c}0.61^{*} \\
(n=20 \\
p<0.001)\end{array}$ & $\begin{array}{c}0.34 * * \\
(n=20 \\
p=0.016)\end{array}$ & $\begin{array}{c}0.20 \\
(n=20 \\
p=0.11)\end{array}$ & $\begin{array}{c}0.06 \\
(n=19 \\
p=0.36)\end{array}$ & $($ ) \\
\hline Mean & 0.49 & 2040 & 12.39 & 0.61 & 561 & 40 \\
\hline$S D$ & 0.51 & 2769 & 3.3 & 0.47 & 1578 & 110 \\
\hline$n$ & 39 & 39 & 31 & 36 & 24 & 20 \\
\hline
\end{tabular}




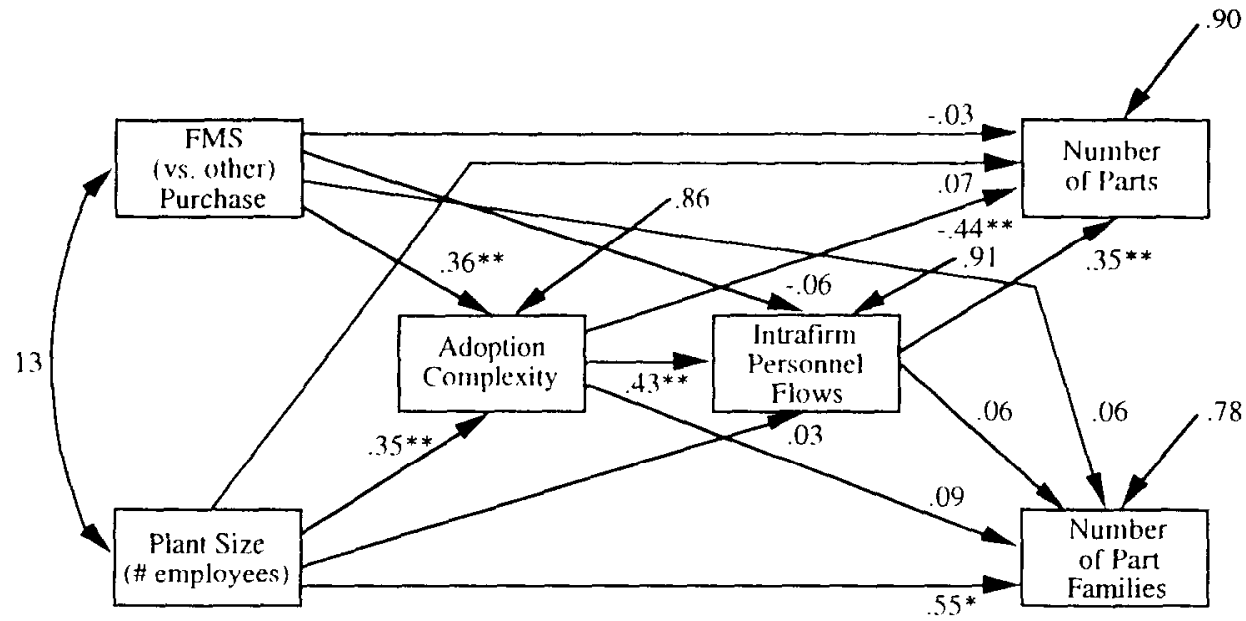

Notes: $\quad * p<0.01$

** $p<0.05$

FIGURE 2

Path Model

In the path analytic diagram (Figure 2), FMS and plant size were taken as exogenous. Number of parts and part families were taken as dependent on personnel flows (intraorganizational) and justification complexity. Personnel flows was taken as dependent on justification complexity. All path coefficients are shown.

Proposition 1 is strongly supported by this model (Figure 2). FMS (vs. cell or other) system purchase and plant size were significant predictors of purchase justification complexity (path coefficients were 0.36 and 0.35 , both significant at the 0.05 level, respectively). These two predictors account for 26 percent of variance in the significant ( $F=6.4, p=0.004$ ) regression for adoption complexity.

Proposition 2 is also supported by results (Figure 2). That is, purchase justification complexity is a significant predictor of personnel flows within the organization for implementation of the new processing system ( path coefficient $=0.43, p<0.05$ ). The three predictors accounted for 18 percent of the variance in intraorganizational personnel flows in the regression $(F=2.5, p=0.075)$.

Proposition 3 was partially supported by the model. Number of parts and families were not a function of FMS purchase, per se (path coefficients were -0.03 and 0.06 , respectively), as predicted. However, personnel flows predicted only parts and not part families ( path coefficients $=0.35, p<0.05$ and path coefficient $=0.06$, n.s., respectively). Adoption complexity had no direct effect on number of part families (path coefficients were 0.09 , n.s.). However, it had an inverse effect on number of parts scheduled (path coefficient $=-0.44, p<0.05$ ).

Proposition 4 was sustained by these results. Plant size was a significant predictor of number of part families (path coefficient $=0.55, p<0.01$ ). However, since neither adoption complexity nor personnel flows had an impact on number of part families, it is clear that future research needs to find the intervening mechanism through which 
structural complexity operates. On the other hand, the four predictors that entered the regression to predict number of part families accounted for a total of 39 percentof the variance which was significant $(F=5.3, p=0.0019)$.

Overall, five of the seven path coefficients were correctly predicted. Therefore, the overall confidence in this model is quite high. The rival hypothesis that radical technology compounds results was evaluated in a second, alternative path model (not shown) taking technology type (radical vs. incremental vs. no new technology) as exogenous. The path coefficient for technology type and adoption was 0.12 (n.s.). An additional six percent of the variance in adoption complexity results to a total of 32 percent explained variance (adjusted $R 2$ improves from 0.22 to 0.26 ). As expected (Ettlie, 1985, 1980), there was also a significant path coefficient for technology type and personnel flow: path coefficient $=0.34(p<0.05)$. However, no other significant path coefficients appear in this alternative model, so this variable was dropped.

\section{Radicalness of Technology and System Cost}

Is technological complexity a function of scale (size) of purchase independent of the radicalness of the new system (cf. Dewar \& Dutton, 1986)? That is, are there complications here in the model between the sophistication of the choice as measured by scale of purchase?

Size of initial investment - the cost of the new manufacturing system was controlled in two ways. The absolute size of the initial investment (which averaged $\$ 5.4$ million for 33 complete data cases on both variables in these analyses, with a standard deviation of $\$ 5.1$ million) as well as the relative investment (cost divided by number of plant employees) were used in partial correlation coefficients. The zero-order correlation between the scale to measure adoption complexity and cost with $r=0.63$ ( $p<0.001$, $n=27$ ). However, the correlation (zero-order) between just the number of reasons given for purchase (first item of the adoption complexity scale) and cost was not significant $(r=0.23, p=0.101, n=33$ ). This is discussed below. The zero-order correlation between the adoption complexity and cost per employee was $r=0.20(n=27, p=0.155)$, which is also not statistically significant.

As it turns out, if just number of purchase reasons (part of adoption complexity) is examined, the same pattern is found whether controlling for cost or cost per employee. For example, when the relationship between the number of reasons for purchase and part families is controlled for by cost and cost per employee, the coefficient becomes $r=0.53(d f=17, p=0.01)$ and $r=0.50(d f=16, p=0.017)$, respectively. That is, controlling for the cost of the investment has virtually no impact on the strength of the relationship of number of purchase reasons with part families. Further, the relationship between the scale to measure adoption complexity and part families is not affected by controlling for the initial cost of the new system per plant employee $(r=$ $0.40, d f=16, p=0.05$ ). The only control cost that appears to have any effect on this relationship is initial cost. Controlling for this figure diminishes this corrclation coefficient to 0.24 ( $d f=16, p=0.17$ ). Recall that the zero-order correlation between purchase complexity and part families was $r=0.38(p=0.048, n=20)$.

Overall, neither radicalness of technology, nor cost of the initial investment, appear to influence the strength of the findings here-that is, adoption complexity appears to focus the unit adopting new flexible technology on economies of scope for their operation. 


\section{DISCUSSION}

As firms change strategic emphasis from economies of scale to economies of scope, a variety of challenges emerge. In particular, it was predicted and found that companies vary considerably in their approach to justification for the adoption and realization of new technologies needed to enhance flexibility of operations. In this study of 39 domestic manufacturing plants in the durable goods industrics, justifications for purchase of new process technology varied from the very simple, single-goal-andmeasure, to the very complex, multiple-objective strategy. This variance in purchase goals was found to be part of a larger construct of adoption complexity which included measures of planning completeness and comprehensiveness.

\section{Research Implications}

Significantly, adoption complexity was found to be a function of FMS (vs. cellular and other approaches to manufacturing) purchase choice and plant size in the path model. Larger plants that purchased FMS used a more complex justification for adoption. These two predictors alone accounted for 26 percent of the variance in adoption complexity. Adding type of technology (radical vs. incremental vs. no new technology incorporation) added only an additional six percent to explained variance. Intrafirm personnel flows were found to be a significant function of adoption complexity. The more complex the justification, apparently, the more effort is required to implement the strategy, and, consequently, the more mobility and rotation of people during implementation. Flexible outcomes are not automatic nor inevitable with more flexible technology. Rather, they result from both structural complexity (as approximated by plant size) and are manifest in more part families scheduled on new manufacturing systems. Adoption complexity was actually found to reduce the number of parts (not part families) scheduled. Personnel flows, on the other hand, promoted more part variety in new production. This suggests that the "technofix" to global competitiveness won't work.

There are several questions that remain unanswered by this study. For example, this theory needs testing in other industries, like the extraction, continuous process manufacturing, and public sectors of the economy; other cultures should be evaluated. What is more, it may be that the theory can be integrated with a more comprehensive model that takes into account the life-cycle of the industry, technical core of the firm and the readiness to add core competence (Prahalad \& Hamel, 1990).

With respect to the evolution of the top management team (Fredrickson \& Iaquinto, 1989), it may be that tenure is not the only variable of interest. For example, as it concerns the results of this study, one might want to include careful consideration of the composition of the team and the nature of the influence of the chief technical officer of the firm on innovation policy. The integration of product and process innovation has become a crucial issue in manufacturing of discrete parts and may not be adequately accounted for in previous research.

These results do imply and raise the question as to how much and what is learned as a new technology is assimilated into an organization. It seems highly unlikely that every person involved in modernization learns the same lessons. Rather, learning ought to be differentiated by position. It is suspected that a complex purchase rationale allows this to happen more readily than single purpose, uncomplicated rationales. This is 
consistent with findings reported recently by Adler and Clark (1991). If firms develop new models of their production processes as a result of modernizing, this should be the subject of future research.

There were data in this study from the predecision stage of these cases, but they were retrospective and hard to verify. Others have reported on the preadoption process (e.g., Graham \& Rosenthal, 1985) about those factors that shape the learning experience. Certainly, there is some reason to believe that not everyone will "learn" at the same pace in this situation. The paradox of this situation results from the tension between creative solutions to problems and making some version of the technology system work - no matter how crude or tentative it might seem to the purist. Creativity will also be required for learning after major design choices have been made. Some positions, occupations, and people will be more comfortable with change as a rule versus an exception. It is not clear how this paradox affects adoption complexity.

One also has to assume, as indicated by our scale development effort, that the key individuals on the decision-making team (e.g., $R \& D$, engineering, manufacturing, and marketing) will contribute significantly to the degree of complexity (or lack thereof) in the purchase rationale. Modernization is a significant challenge for even the most sophisticated manufacturing organizations. It might be argued that the capacity to learn from this experience is reflected in part by its impact on the decision-making process as it evolves and the assumptions and models these decisions represent. Further, the clustering of stages into phases may be a consequence of comprehensiveness in practice for innovative decision units.

One of the underlying assumptions that seems to be implied by these results is that the innovation process and the creation of change does not end when a major decision is taken. Rather, the change process is punctuated by significant events which ultimately lead to emergent dominant designs, the ultimate stcady-state outcomes of any major technological shift (Anderson \& Tushman, 1990). Research needs to attend more to these processes surrounding significant adoption decisions and attempts should be made to understand how they influence the policies and cultures of organizations in a permanent way. Further, there is a need to continue to explore the relationship between individual cognition and the organizational consequences of decision makers making choices new technologies in the firm. Is the next level of aggregation of cognitive complexity truly manifest in adoption complexity?

\section{Management and Public Policy Implications}

Some of the implications for managing transition in manufacturing seem quite clear from these results. Satisfying customers by being able to switch easily among part families needs to be emphasized in addition to traditional measures of productivity in most plants. If the connection between available performance measures and satisfying customers exists, then by all means, consider new productivity measures like time-based competition measures. Further, the nontraditional aspects of learning that actually might impede the progress function need to be attended to. A new model of the role of innovation in production might result.

Perhaps the most important empirical finding of this research with management and public policy implications is the distribution of the number of reasons for purchase of a new technology manufacturing system. Most firms gave two reasons (15 cases) 
or one reason (10 cases). Many fewer plants or divisions gave more than two reasons: in eight cases, three reasons were given; only four cases gave four reasons and one case each gave five and six reasons respectively. FMS adopters in large plants give more complex rationales for adoption, including more reasons for purchase-not just productivity enhancement.

There are three important implications of these results. First, managing larger plants (i.e., more than 200-300 people) requires an understanding of the core technology production process that goes beyond the small white cards that supervisors carry around in their pockets that often contain the critical items to be satisfied for production in a given day. As one recent representative of the Society of Manufacturing Engineering's award for computer-integrated manufacturing put it: "We adopted integrated manufacturing for quality reasons, but we beat all cycle time and productivity targets, as well." In each plant there is a complex relationship between various output measures, but only those that matter to the customer ought to be part of the productivity equation and rationale for modernization. This, in-and-of-itself is a challenge.

Second, in smaller plants and firms, the relationship between the understanding of the complexity of the adopting new process technology and performance outcomes may be more apparcnt, but the resources needed to implement a complex new technology may not be easily obtained. A few, small, modern manufacturing firms have somehow learned how to do it. Kreuger Machine Tool Company in Michigan is an example of such a firm. In order to make up for the absence of critical human and technological resources, this small company that makes special purpose machine tools for the automotive industry, has found a way. Bruce Moore, the President of Kreuger, says that the help of such government sponsored organizations as the Michigan Manufacturing Technology Center in Ann Arbor, Michigan, funded in part through Federal grants, is essential to leveraged change for small companies. This is a win-win situation: the MTC (Manufacturing Technology Center) learns and contributes to their knowledge base on how to help small firms, and aggressive small firms learn how to modernize on a budget and a firms like Chrysler Corporation, a Kreuger customer, benefit by having up-to-date suppliers of equipment.

Third and finally, these results on adoption complexity reinforce the recommendations of Kaplan and Atkinson (1989, pp. 473-492) that the prudent application of the Discounted Cash Flow (DCF) approach to justification of new manufacturing technology requires a betler understanding of what are the actual costs and benefits of modernization with flexibility. Ideas such as including training and software in the appropriation request are now warranted.

The outstanding public policy question is how more firms might assume this profile of new, apparently quite rare, complex models of a modern manufacturing facility of the next century. Until most, not just a few, companies have at least three or four integrated reasons for modernization, the struggle continues. At some point, the ecology (e.g., pollution prevention) ought to enter into these adoption justifications.

\section{ACKNOWLEDGEMENTS}

Work in this area was supported in part by the National Science Foundation and The University of Michigan. The opinions herein are those of the authors and do not 
necessarily reflect the official position of the National Science Foundation. Earlier versions of this paper were presented at the Second International Conference on Engineering Management in Toronto, Canada on September 10-13, 1989, and at the Decision Sciences Institute 20th Annual Meeting in New Orleans, LA, November 20 $22,1989$.

\section{APPENDIX}

\section{Items for Comprehensiveness Scale in Post-Purchase Rationale}

1. Why was the system purchased?

(Coded for Number of Reasons)

2. We use teams in the system to accomplish work?

$\begin{array}{ccc}\text { YES } & \text { NO } & \text { IN PROCESS* } \\ 1 & 2 & 3 \\ 1 & 2 & 3 \\ 1 & 2 & 3 \\ 1 & 2 & 3\end{array}$

4. Our R\&D units was involved in the designing of this system

5. We have a corporate manufacturing engineering function

6. Is it never too early to include suppliers in a program for modernization?

12

(IF YES) Explain:

Notes: $*$ Items are recoded as Yes $=3, \mathrm{No}=1$ and In-process $=2$. The last item on suppliers is recoded $\mathrm{Yes}=3$ and $\mathrm{N}_{0}=$ I. Note, the last item can be used as a check on faking because it can be perceived to be counter-intuitive.

\section{REFERENCES}

Adler, P.S., \& Clark, K.B. (1991). Behind the learning curve: A sketch of the learning process. Management Science, 37(3), 267-81.

Anderson, P., \& Tushman, M.L. (1990). Technological discontinuities and dominant designs: A cyclical model of technological change. Administrative Science Quarterly, 35(4), 60433.

Booz, Allen, \& Hamilton, Inc. (1982). New products management for the 1980 's. New York: Booz, Allen, and Hamilton, Inc.

Burstein, M.C., \& Graham, P. (1989). Strategic justification of CIM: A systematic, market-based approach for plant determination of distinctive manufacturing capabilities. Working paper for the MI90 Conference Proceedings of the ASME. Detroit, MI.

Collins, P. D., Hage, J., \& Hull, F.M. (1988). Organizational and technological predictors of change in automaticity. Academy of Management Journal, 3l(3), 512-43.

Cyert, R., \& March, J. (1963). A behavioral theory of the firm. Englewood Cliffs, N.J.: PrenticeHall.

Dearborn, D.C., \& Simon, H.A. (1958). Selective perception: A note on the department identifications of executives. Sociometry, 21, 140-44.

Dewar, R.D., \& Dutton, J.E. (1986). The adoption of radical and incremental innovations: An empirical analysis. Management Science, 32(11), 1422-1433.

Ettlie, J.E. (1990). Intrafirm mobility and manufacturing modernization. Journal of Engineering and Technologv Management, 6(3/4), 281-302. 
Ettlie, J.E. (1988). Taking charge of manufacturing. San Francisco, CA: Jossey-Bass Publishers.

Fttlie, J.F., \& Rosenthal, S. (1987). Strategic deployment of FMS: What we are learning in the 1980 's. "Presented at the ORSA/TIMS Meeting, New Orleans, LA.

Ettlie, J.E. (1985, Sept.). The impact of interorganizational manpower flows on the innovation process. Management Science, 31(9), 1055-1071.

Ettlie, J.E., Bridges, W., \& O'Keefe, R. (1984). Organizational strategy and structural differences for radical versus incremental innovation. Management Science, 30(6), 632-95.

Ettlie, J.E. (1980, Nov.). Manpower flows and the innovation process. Management Science, 26(11), 1086-1095.

Farley, J., Kahn, B., Lehmann, D., \& Moore, W. (1987). Modeling the choice to automate, Sloan Management Review, 5-15.

Fredrickson, J.W., \& Iaquinto, A.L. (1989). Inertia and creeping rationality in strategic decision process. Academy of Management Journal, 32(3), 516-42.

Frceman, C. (1982). The economics of industrial innovation. Cambridge, MA: MIT Prcss.

Gerwin, D., \& Tarondeau, J. (1988). International comparisons of manufacturing flexibility. Working paper, School of Business Administration, University of Wisconsin-Milwaukee.

Goldhar, J.D., \& Jelinek, M. (1990). Manufacturing as a service business: CIM in the 21 st century. Computers in Industry, 14(1-3), 225-45.

Goldhar, J.P., \& Jelinek, M. (1983). Plan for economics of scope. Harvard Business Review, 141-48.

Graham, M.B.W., \& Rosenthal, S.R. (1985). Flexible manufacturing systems require flexible people. Paper presented at the TIMS/ORSA meeting, Atlanta, GA.

Grinyer, P.H., \& Norburn, D. (1975). Planning for existing markets: Perceptions of executives and financial performance. Journal of Royal Statistical Society, Series A: 138(1), 70-97.

Hagarty, W. H., \& Hoffman, R.C. (1990). The relationship between strategic planning and performance among three cultures. Academy of Management Proceedings. San Francisco: CA.

Hage, J. (1980). Theories of organization: Form, process, and transformation. New York: Wiley.

Hambrick, D.C. (1983). Some tests of the effectiveness and functional attributes of Miles and Snow's strategic types. Academy of Management Journal, 26, 5-26.

Jaikumar, R. (1986, Nov/Dec.). Post-industrial manufacturing. Harvard Business Review, 6976.

Kaplan, R.S., \& Atkinson, A.A., (1989). Advanced management accounting (2nd Ed.). Englewood Cliffs, NJ: Prentice Hall.

Kim, J., \& Mueller, C.W. (1978). Factor analysis. Beverly Hills, CA: Sage Publications.

Kolodny, H., \& Stjernberg, T. (1986). The change process in innovative work designs: New design and redesign in Sweden, Canada and the U.S.A. Journal of Applied Behavioral Science, 22(3), 287-302.

Lim, S.H. (1987). Flexible manufacturing systems and manufacturing flexibility in the United Kingdom. International Journal of Production and Operations Management, 7(6), 24-26.

March, J.G., \& Simon, H.A. (1958). Organizations. New York: Wiley.

Mason, R., \& Mitroff, I. (1981). Challenging strategic planning assumptions. New York: Wiley. Milgrom, P., \& Roberts, J. (1990, June). The economics of modern manufacturing: Technology, strategy and organization. The American Economic Review, 90(3), 511-28.

Nunnally, J.C. (1978). Psychometric theory (2nd Ed.). New York, NY: McGraw-Hill.

O'Reilly, C.A. (1983). The use of information in organizational decision making: A model and some propositions. In L.L. Cummings \& B.M. Staw (Eds.), Research in organizational behavior (Vol. 5, pp. 103-39). Greenwich, CT: JAI Press.

Prahalad, C.K., \& Hamel, G. (1990). The core competence of the corporation. Harvard Business Review, 68, 79-87.

Roskin, R., \& Margerison, C. (1984). Situational complexity and managerial achievement. Management International Review, 24(3), 46-52. 
Simon, H.A. (1957). Models of man. New York: Wiley.

Skinner, W. (1986). The productivity paradox. Harvard Business Review, 64, 55-59.

Stagner, R. (1969). Corporate decision making: An empirical study. Journal of Applied Psychology, 53, 1-13.

Turner, B.A. (1976). The organizational and interorganizational development of disasters. Administrative Science Quarterly, 21, 378-97.

U.S. Department of Commerce. (1989, May). Bureau of census report, manufacturing technology 1988. Author.

Van de Ven, A.H. (1986). Central problems in the management of innovation. Management Science, 32(5), 590-607.

Van de Ven, A.H., \& Poole, M.S. (1990). Methods for standing innovation development in the Minnesota innovation research Program. Organization Science, 1(3), 313-35.

Walsh, J.P. (1988). Selectivity and selective perception: An investigation of managers; Belief structures and information processing. Academy' of Management Journal, 3I(4), 873-96.

Weick, K.E. (1979). Social psychology of organizing. Reading, MA: Addison-Wesley Publishing Company.

Wilensky, H.L. (1967). Organizational intelligence. Ncw York: Basic Books.

Wood, D., Robley, Jr., \& Laforge, R.L. (1981). Toward the development of a planning scale: An example from the banking industry. Strategic Management Journal, 2, 209-16.

Wyden, P. (1979). Bay of pigs. New York: Simon \& Schuster. 